\title{
Ovol2, a zinc finger transcription factor, is dispensable for spermatogenesis in mice
}

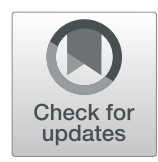

Jin Zhang ${ }^{1,2+}$, Juan Dong ${ }^{1+}$, Weibing Qin $^{3+}$, Congcong Cao ${ }^{1}$, Yujiao Wen ${ }^{1}$, Yunge Tang ${ }^{3 *}$ and Shuiqiao Yuan ${ }^{1,4^{*}}$ (D)

\begin{abstract}
Ovol2, a mouse homolog of Drosophila ovo, was identified as a zinc finger transcription factor predominantly expressed in testis. However, the function of Ovol2 in postnatal male germ cell development remains enigmatic. Here, we firstly examined the mRNA and protein levels of Ovol2 in developing mouse testes by RT-gPCR and western blot and found that both mRNA and protein of Ovol2 are continually expressed in postnatal developing testes from postnatal day 0 (P0) testes to adult testes (P56) and exhibits its higher level at adult testis. Further testicular immuno-staining revealed that OVOL2 is highly expressed in the spermatogonia, spermatocytes and round spermatids. Interestingly, our conditional ovol2 knockout mouse model show that loss of ovol2 in embryonic germ cells does not affect fecundity in mice. Our data also show that Ovol1 may have compensated for the loss of Ovol 2 functions in germ cells. Overall, our data indicate that ovol 2 is dispensable for germ cell development and spermatogenesis.
\end{abstract}

Keywords: Ovol2, Spermatogenesis, Fertility, Knockout mice

\section{Main text}

Ovol2, a mouse homolog of Drosophila ovo, was identified as a zinc finger transcription factor predominantly expressed in testis [1]. Previous studies revealed that Ovol2 exhibits its functions in keratinocyte transient proliferation and differentiation [2], mouse embryonic stem cells differentiation [3] and primordial germ cell development [4]. However, the function of Ovol2 in postnatal male germ cell development remains enigmatic. Thus, we firstly examined the mRNA and protein levels of Ovol2 in multiple adult mouse tissues by RTqPCR and western blot. We found that both the mRNA and protein of Ovol2 are highly expressed in testis and lung (Fig. 1a-c). We then examined the expression levels of Ovol2 in postnatal developing testes and found that both mRNA and protein of Ovol2 are continually expressed in postnatal developing testes from postnatal day 0 (P0) testes to adult testes (P56) and exhibits its

\footnotetext{
*Correspondence: tyg813@126.com; shuiqiaoyuan@hust.edu.cn

${ }^{\dagger}$ Jin Zhang, Juan Dong and Weibing Qin contributed equally to this work.

${ }^{3} \mathrm{NHC}$ Key Laboratory of Male Reproduction and Genetics, Family Planning Research Institute of Guangdong Province, Guangzhou, People's Republic of China

${ }^{1}$ Institute of Reproductive Health, Tongji Medical College, Huazhong

University of Science and Technology, Wuhan, People's Republic of China Full list of author information is available at the end of the article
}

highest level at adult testis (Fig. 1d-f). Further testicular immuno-staining revealed that OVOL2 is highly expressed in the germ cells (spermatogonia, spermatocytes and round spermatids) (Fig. $1 \mathrm{~g}$ and Additional file 1: Figure S1A-D). Thus we hypothesized that Ovol2 could play an important role in postnatal germ cell development and spermatogenesis.

Due to Ovol2 conventional mutant mice displayed an embryonic mortality [4], we tried to specific knockout of Ovol2 in mouse germ cells to determine the physiological roles of Ovol2 in germ cell development. We then generated Ovol2 conditional knockout mouse model by crossing Ovol2-floxed mice with Vasa-cre (Cre was specifically activated at embryonic day 15.5) to inactive Ovol2 gene in testicular germ cells (Fig. 2a). The genotype of Ovol2 germ cell-specific knockout mice (Vasa-Cre; Ovol2 ${ }^{\text {floxfllox }}$, hereafter called Vasa-cKO) was confirmed by PCR-based genotyping analyses (Fig. 2b). In addition to genotyping analyses, both mRNA and proteins of Ovol2 were appeared to be significantly reduced in Vasa-cKO testes compared with that of WT controls by RT-qPCR, Western blot and Immunofluorescence analyses (Fig. 2c-e and Additional file 1: Figure S1E). Therefore, these data suggest that Ovol2 was specifically inactivated in testes efficiently. 


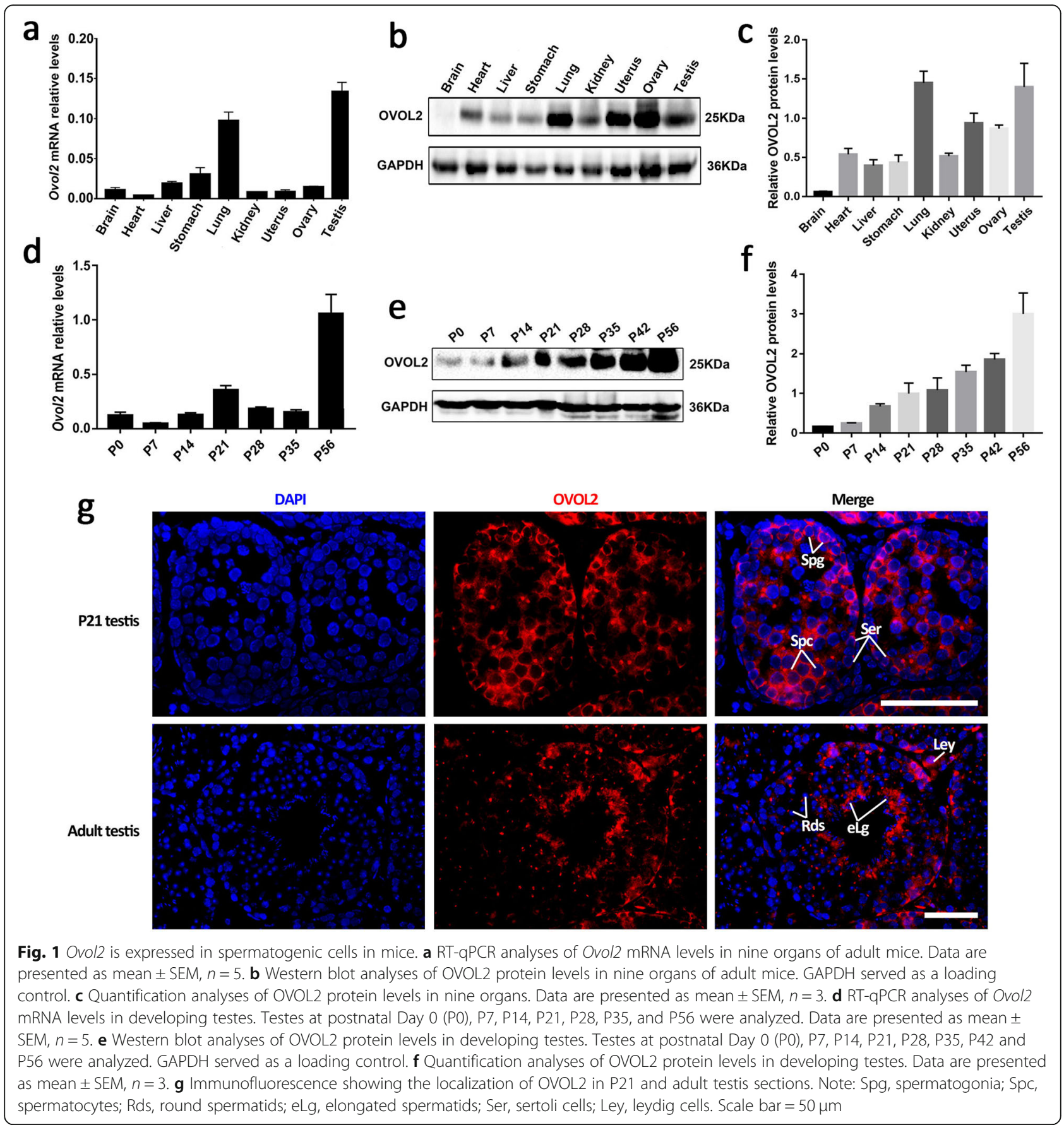

To investigate the fertility of Vasa-cKO mice, we bred the Vasa-cKO males with fertility-proven WT females for at least 5 months. Unexpectedly, VasacKO breeding pairs can produce comparable litter size to WT breeding pairs (data not shown), which indicated that Vasa-cKO male mice are completely fertile. Consistent with this fertile phenotype, testis gross morphology and weights are comparable between Vasa-cKO and WT control mice (Fig. 2f-g). Histological analyses further revealed that Vasa-cKO testes display normal spermatogenesis (Fig. 2h). To further confirm the Vasa-Cre recombined deletion efficiency in DNA level, we detected the delete allele of Ovol2 in the offspring derived from Vasa-cKO male breeding pairs by PCR-based DNA analyses. As we expected, all of pups are contained Ovol2 delete allele (Additional file 1: Figure S2). Together, these data indicate that Ovol2 is not essential for spermatogenesis and male germ cell development in mice despite its high expression in testis. 


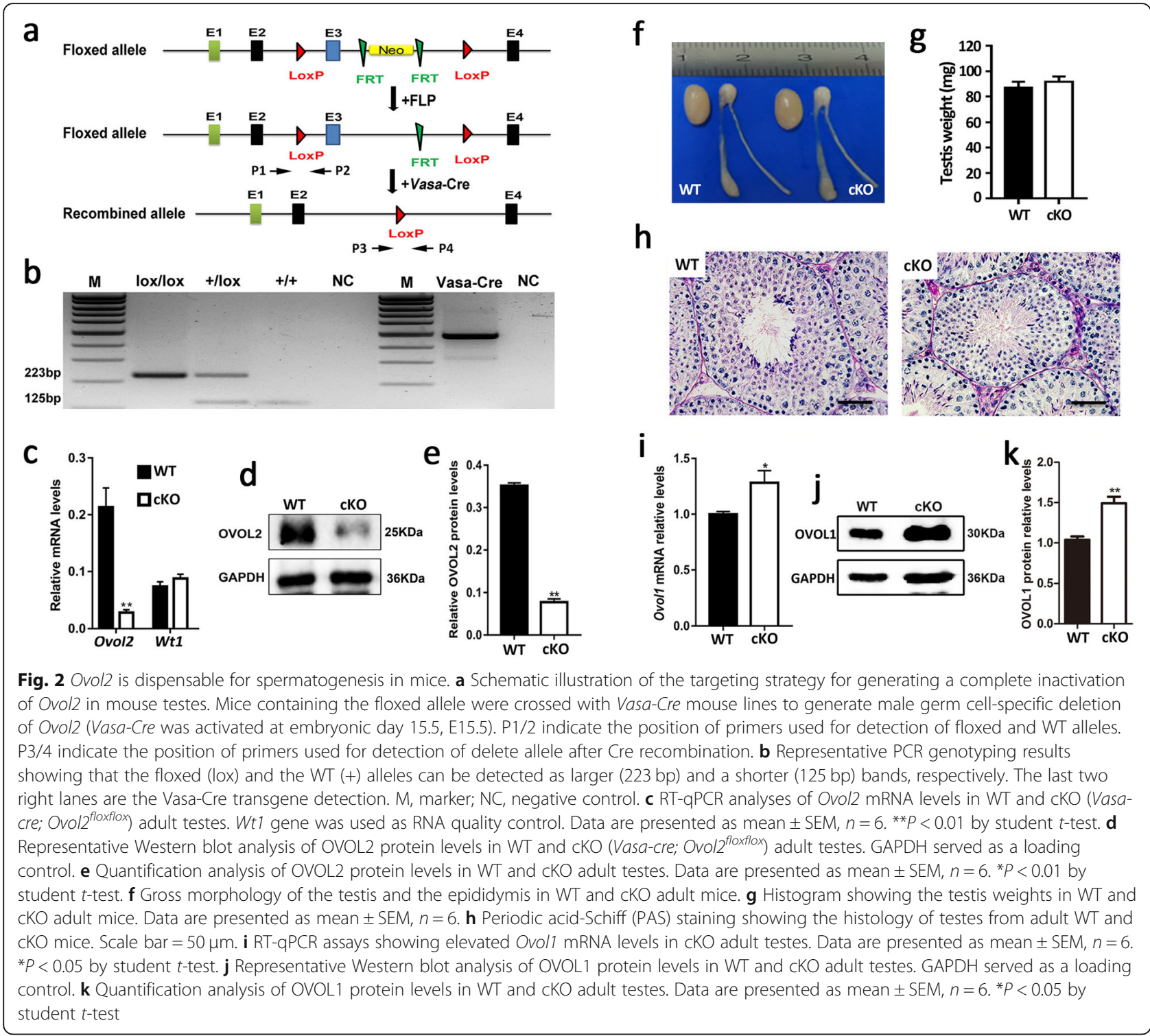

Ovol1, another Drosophila ovo mouse homologue, was confirmed to express in overlapping tissues with Ovol2, such as skin, kidney and testis. Ablation of Ovol1 in mice led to abnormal male germ cell development and male infertility, and Ovol1 is essential for spermatogenesis [5]. Thus, we analyzed the expression levels of Ovol1 in adult WT and Vasa-cKO testes by RT-qPCR. Interestingly, both Ovol1 mRNA and protein levels were significantly increased in Vasa-cKO testes compared with those of WT testes (Fig. 2i-k). Therefore, these data suggest that Ovol1 may have compensated for the loss of Ovol2 functions in germ cells, which leads to normal phenotype in Vasa-Cre;Ovol2 $2^{l o x / l o x}$ mice. However, it is worthwhile pointing out that other transcription factors need to be elucidated in future, which may contribute to the compensation of OVOL2 loss-of -function in male germ cells. Overall, in this study, we report that Ovol2 is dispensable for testicular germ cell development and spermatogenesis in mice, and provide a molecular therapeutic clue for human male infertility caused by genetic mutation.

\section{Conclusion}

Both mRNA and protein of Ovol2 are continually expressed in postnatal developing testes from postnatal day 0 (P0) testes to adult testes (P56) and exhibits its highest level at adult testis. Ovol2 is dispensable for testicular germ cell development and spermatogenesis in mice. Ovol1 may have compensated for the loss of Ovol2 functions in germ cells, which leads to normal phenotype in Ovol2 conditional mutation mice. 


\section{Supplementary information}

Supplementary information accompanies this paper at https://doi.org/10. 1186/s12958-019-0542-3.

Additional file 1: Figure S1: The localization of OVOL2 in mouse testicular sections was revealed by immunofluorescence. (A) Co--immunofluorescent staining for OVOL2 and WT1 (a Sertoli cell marker) antibodies on P21 WT testicular section showing OVOL2 expressed in Sertoli cells. Nuclei were stained with DAPI. (B) Co--immunofluorescent staining for OVOL2 and $y-$ H2A.X antibodies on P21 testicular section showing OVOL2 expressed in pachytene spermatocytes. Nuclei were stained with DAPI. (C) Co-- immunofluorescent staining for OVOL2 and $\mathrm{Y}-\mathrm{H} 2 \mathrm{~A} . \mathrm{X}$ antibodies on P56 testicular section showing OVOL2 expressed in round spermatids. Nuclei were stained with DAPI. (D) Co-immunofluorescent staining for OVOL2 and $\mathrm{\gamma}-\mathrm{H} 2 \mathrm{~A} . \mathrm{X}$ antibodies on P56 testicular section showing OVOL2 expressed in elongating spermatids. Nuclei were stained with DAPI. (E) Co-immunofluorescent staining for OVOL2 and Y-H2A.X antibodies on WT and Vasa--CKO (Vasa--cre; Ovol2lox/lox) testis sections at adulthood. Nuclei were stained with DAPI. Arrowheads indicate Sertoli cell; Arrows indicate Leydig cells. Scale bar bar $=50 \mu \mathrm{m}$. Figure S2. PCR based genotyping of the offspring derived from the Vasa-cKO (Vasa-- cre; Ovol2lox/ del) male breeding pairs. All pups are contains delete allele.

\section{Acknowledgments}

Not applicable.

\section{Available of data and materials}

The data and materials for supporting the conclusion of this short communication are included within the article.

\section{Ethics and approval}

All the animal procedures were approved by the Institutional Animal Care and Use Committee (IACUC) of Tongji Medical College, Huazhong University of Science and Technology, and the mice were housed in the specific pathogen-free facility of Huazhong University of Science and Technology. All experiments with mice were conducted ethically according to the Guide for the Care and Use of Laboratory Animal guidelines.

\section{Authors' contributions}

SY conceived and designed the study. JZ, JD, WQ, CC, and YW performed all bench experiments. JD and SY wrote the manuscript. SY and YT. supervised the project. All authors read and approved the final manuscript.

\section{Funding}

This work supported by grants from National Natural Science Foundation of China (31671551 to S.Y.), the Science Technology and Innovation Commission of Shenzhen Municipality (JCYJ20170244 to S.Y.), Natural Science Foundation of Hubei Province (2017CFA069 to S.Y.).

\section{Consent for publication}

Not applicable.

\section{Competing interests}

The authors declare that they have no completing interests.

\section{Author details}

${ }^{1}$ Institute of Reproductive Health, Tongji Medical College, Huazhong University of Science and Technology, Wuhan, People's Republic of China. ${ }^{2}$ College of Animal Science and Technology, Northwest A\&F University, Yangling, People's Republic of China. ${ }^{3} \mathrm{NHC}$ Key Laboratory of Male Reproduction and Genetics, Family Planning Research Institute of Guangdong Province, Guangzhou, People's Republic of China. ${ }^{4}$ Shenzhen Huazhong University of Science and Technology Research Institute, Shenzhen, People's Republic of China.
Received: 8 August 2019 Accepted: 12 November 2019

Published online: 23 November 2019

\section{References}

1. Masu Y, Ikeda S, Okuda-Ashitaka E, Sato E, Ito S. Expression of murine novel zinc finger proteins highly homologous to Drosophila ovo gene product in testis. FEBS Lett. 1998;421:224-8.

2. Wells J, Lee B, Cai AQ, Karapetyan A, Lee WJ, Rugg E, Sinha S, Nie Q, Dai X Ovol2 suppresses cell cycling and terminal differentiation of keratinocytes by directly repressing C-Myc and Notch1. J Biol Chem. 2009;284:29125-35.

3. Zhang T, Zhu Q, Xie Z, Chen Y, Qiao Y, Li L, Jing N. The zinc finger transcription factor Ovol2 acts downstream of the bone morphogenetic protein pathway to regulate the cell fate decision between neuroectoderm and mesendoderm. J Biol Chem. 2013;288:6166-77.

4. Hayashi M, Shinozuka Y, Shigenobu S, Sato M, Sugimoto M, Ito S, Abe K Kobayashi S. Conserved role of Ovo in germline development in mouse and Drosophila. Sci Rep. 2017;7:40056.

5. Li B, Nair M, Mackay DR, Bilanchone V, Hu M, Fallahi M, Song H, Dai Q, Cohen PE, Dai X. Ovol1 regulates meiotic pachytene progression during spermatogenesis by repressing Id2 expression. Development. 2005;132:1463-73.

\section{Publisher's Note}

Springer Nature remains neutral with regard to jurisdictional claims in published maps and institutional affiliations.

\section{Ready to submit your research? Choose BMC and benefit from:}

- fast, convenient online submission

- thorough peer review by experienced researchers in your field

- rapid publication on acceptance

- support for research data, including large and complex data types

- gold Open Access which fosters wider collaboration and increased citations

- maximum visibility for your research: over $100 \mathrm{M}$ website views per year

At $\mathrm{BMC}$, research is always in progress.

Learn more biomedcentral.com/submission 